\title{
Otimização do processo de extração de $\beta$-xilosidase por sistemas micelares reversos
}

\author{
Daniela Vieira Cortez ${ }^{1}$, Francislene Andréa Hasmann ${ }^{3}$, Adalberto Pessoa Jr. ${ }^{2 *}$, \\ Inês Conceição Roberto ${ }^{1}$
}

\begin{abstract}
${ }^{1}$ Departamento de Biotecnologia - Faculdade de Engenharia Química de Lorena, ${ }^{2}$ Departamento de Tecnologia Bioquímico-Farmacêutica,Faculdade de Ciências Farmacêuticas, Universidade de São Paulo, ${ }^{3}$ Pós-Graduação Interunidades em Biotecnologia IPT/BUTANTAN/USP
\end{abstract}

*Correspondência:

Pessoa-Jr

Departamento de Tecnologia

Bioquímico-Farmacêutica

FCF-Universidade de São Paulo

Av. Prof. Lineu Prestes, 580, Bloco 16

05508-900 - São Paulo-SP-Brasil

Email: pessoajr@usp.br
A enzima $\beta$-xilosidase, produzida pelo fungo Penicillium janthinellum, foi extraida pelo sistema micelar reverso formado pelo agente tensoativo cationico CTAB em isoctano, hexanol e butanol. Os efeitos combinados da concentração de CTAB e de butanol sobre a extração da enzima foram estudados empregandose a metodologia de superficie de resposta. A partir dos resultados obtidos, foi proposto um modelo matemático para descrever o processo de extração da $\beta$-xilosidase na região de trabalho estudada. De acordo com a equação do modelo, podem ser obtidos valores máximos de recuperação de 35,05 $\pm 6,40 \%$ nas seguintes condições: $p H$ 8,0, concentração de CTAB 0,2 M, concentração de hexanol $5 \%$ e concentração de butanol 20\%. Nestas condições, foram realizados novos experimentos e o valor médio de recuperação obtido foi de $38 \%$.

\section{INTRODUÇÃO}

As xilanases, enzimas constituídas de endoxilanase e $\beta$-xilosidase, desempenham importante papel nas reações de hidrólise da xilana, que é um dos principais componentes da fração hemicelulósica de biomassas lignocelulósicas (Biely, 1985). Este complexo enzimático tem potencial de aplicação em diferentes setores industriais, principalmente na etapa de pré-branqueamento da polpa Kraft na indústria de papel e celulose (Sunna, Antrankian, 1997). Recentemente, especial atenção tem sido dada ao uso da enzima $\beta$-xilosidase purificada devido à sua importância biológica, como em reações de transxilosilação na síntese de $\beta$-xilosídeos (Pan et al.,
2001). Várias técnicas para extração e purificação de $\beta$ xilosidase, incluindo precipitação e extração líquido-líquido, têm sido reportadas (Pan et al., 2001; Hasmann et al. 2001; Cortez, Pessoa Jr, 1999). Dentre estas, a extração líquido-líquido por micelas reversas tem sido apontada como uma técnica altamente seletiva e biocompatível na recuperação e concentração de proteínas e outras biomoléculas (Kilikian et al., 2000; Krei, Hustedt, 1992). Um sistema micelar reverso consiste de agregados de moléculas de agentes tensoativos dispersas em meio orgânico contendo em seu interior um núcleo aquoso. $\mathrm{O}$ microambiente polar dentro da micela reversa permite a solubilização de proteínas. O processo de extração é governado principalmente, por interações eletrostáticas e, 
portanto, o valor do $\mathrm{pH}$ da fase aquosa deve ser tal que a carga líquida na superfície das proteínas seja eletricamente oposta àquelas da cabeça dos tensoativos (Hasmann et al., 2001). Proteínas também podem ser extraídas por interações hidrofóbicas entre regiões apolares da molécula e a cauda apolar do tensoativo (Hasmann et al., 1999; Luisi et al., 1988). Na etapa de re-extração (liberação das proteínas do sistema micelar reverso) o valor do $\mathrm{pH}$ deve ser tal que a proteína tenha a mesma carga da cabeça polar do tensoativo para que sejam criadas forças de repulsão e conseqüente expulsão da proteína do interior da micela reversa. Nessa etapa, o aumento da força iônica irá diminuir o diâmetro das micelas, causando assim a liberação da proteína das micelas reversas (Krei, Hustedt, 1992; Pessoa-Jr, Vitolo, 1998; Leser, Luisi, 1990). Esta técnica é, portanto, particularmente interessante para a recuperação de enzimas extracelulares.

A extração e purificação de $\beta$-xylosidase tem sido investigada com particular referência ao rendimento do processo de extração com base na recuperação da atividade enzimática. No processo de extração líquido-líquido por micelas reversas, a transferência da biomolécula da fase aquosa para a pseudofase micelar depende da natureza do solvente, co-solvente, tipo e concentração do tensoativo e $\mathrm{pH}$, dentre outros fatores. Em trabalho anterior foi verificado que, sob condições alcalinas $(\mathrm{pH}=8,0)$, a concentração de tensoativo (CTAB) e de butanol são as principais variáveis que influenciam nos resultados de recuperação da enzima $\beta$-xilosidase (Hasmann et al., 2001). Portanto o objetivo deste trabalho foi otimizar essas duas através de um planejamento estatístico fatorial composto empregando a metodologia de superfície de resposta.

\section{MATERIAL E MÉTODOS}

\section{Microrganismo e Obtenção de Esporos}

O microrganismo utilizado no presente trabalho, o fungo Penicillium janthinellum CRC 87M-115, foi isolado em Lorena-SP a partir de madeira em decomposição (Milagres, 1988). O meio de cultura usado para obtenção de esporos de $P$. janthinellum foi composto por $2 \%$ de glicose, $0,25 \%$ de extrato de levedura, $2 \%(\mathrm{v} / \mathrm{v})$ de solução mineral de VOGEL, e 2\% de ágar-ágar. Aproximadamente, $5 \mathrm{~mL}$ do meio de cultura foram transferidos para tubos de ensaio, os quais foram autoclavados por $15 \mathrm{mi}-$ nutos a $112^{\circ} \mathrm{C}$ e deixados em superfície inclinada (aproximadamente $20^{\circ}$ ). Após resfriamento, os tubos foram inoculados com esporos de P. janthinellum de um tubo matriz e incubados em estufa termostatizada a $30^{\circ} \mathrm{C}$, por
5 dias. Os esporos foram então suspensos em água esterilizada e utilizados como inóculo no processo fermentativo.

\section{Meio e Condições de Fermentação}

Nos ensaios de fermentação para obtenção do complexo xilanolítico, utilizou-se como substrato o hidrolisado hemicelulósico de bagaço de cana-de-açúcar, obtido por hidrólise ácida conforme descrito por Milagres, Lacis (1991). O meio de cultivo foi composto de hidrolisado, solução mineral de Vogel $(2 \% \mathrm{v} / \mathrm{v})$ e extrato de levedura $(0,1 \%)$. Frascos erlenmeyers de $125 \mathrm{~mL}$ contendo $25 \mathrm{~mL}$ do meio de cultivo foram inoculados com $1 \mathrm{~mL}$ de solução de esporos contendo aproximadamente $10^{5}$ esporos $/ \mathrm{mL}$ e incubados a $30^{\circ} \mathrm{C}$ sob agitação de $60 \mathrm{rpm}$ por 5-7 dias em agitador orbital. O meio fermentado foi separado das células por filtração em papel, homogeneizado para garantia da uniformidade e estocado à temperatura de $-4{ }^{\circ} \mathrm{C}$.

\section{Atividade Enzimática}

A atividade da $\beta$-xilosidase foi determinada através da quantidade de $p$-nitrofenol (pNP) liberada em meio reacional contendo $p$-nitrofenil- $\beta$-D-xilopiranosídeo (pNpX) como substrato (Kumar, Ramón, 1996). Para o ensaio de atividade, a mistura reacional contendo $250 \mu \mathrm{L}$ do meio fermentado diluído em tampão acetato de sódio $(50 \mathrm{mM}, \mathrm{pH} 5,5)$ e $250 \mu \mathrm{L}$ solução de pNpX $(2 \mathrm{mM})$ foi incubada a $50{ }^{\circ} \mathrm{C}$ por 30 minutos. A reação foi interrompida pela adição de $1 \mathrm{~mL}$ de solução de carbonato de sódio (2 M). As leituras de absorvância foram feitas a $400 \mathrm{~nm}$ em espectrofotômetro marca BECKMAN ${ }^{\circledR}$ DU 6408. Uma unidade de atividade de $\beta$-xilosidase foi definida como a quantidade de enzima necessária para liberar 1 mmol de $p$-nitrofenol por minuto.

\section{Extração de $\beta$-xilosidase por Micela Reversa}

A enzima $\beta$-xilosidase foi extraída do meio fermentado por micelas reversas do agente tensoativo catiônico CTAB empregando-se isoctano como solvente e hexanol e butanol como co-solventes. Para o preparo das microemulsões, as concentrações de CTAB e de butanol foram aquelas descritas no planejamento experimental, sendo as proporções hexanol/isooctano mantidas em 5/95\%. Na etapa de extração, 5,0 mL do meio fermentado (MF) tamponado com tris- $\mathrm{HCl}(\mathrm{pH} 8,0)$ na proporção 1(tampão):9(meio) foi misturado com 5,0 mL de microemulsão. Após agitação em vórtice por 1 minuto, 
seguida de centrifugação a $1677 x g$ por 10 minutos obteve-se o equilíbrio entre as fases aquosa (FAI) e orgânica ou pseudofase micelar (FMI). Na etapa de re-extração, $2 \mathrm{~mL}$ do líquido da fase micelar (FMI) foram misturados com 2,0 mL de tampão acetato de sódio $1 \mathrm{M}, \mathrm{pH}$ 5,5 contendo $1 \mathrm{M}$ de $\mathrm{NaCl}$. Também por agitação em vórtice por $1 \mathrm{mi}-$ nuto, seguida de centrifugação a $1677 \mathrm{xg}$ por 10 minutos, uma nova fase aquosa (FAII) contendo a enzima foi obtida. Os resultados de extração foram expressos em porcentagem de recuperação $\mathrm{Y}(\%)$, conforme Equação 1.

$$
Y(\%)=\left(\frac{A_{F A I I}}{A_{M F}}\right) X 100
$$

onde:

$\mathrm{A}_{\mathrm{FAII}}=$ atividade na fase aquosa II (U);

$\mathrm{A}_{\mathrm{MF}}=$ atividade no meio fermentado (U)

\section{Delineamento Experimental}

Para determinar as condições ótimas de recuperação de $\beta$-xilosidase utilizou-se um planejamento fatorial completo $2^{2}$ com distribuição ortogonal $\left(\alpha= \pm 2^{1 / 2}\right)$. As variáveis selecionadas para o estudo da recuperação da $\beta$-xilosidase foram: concentração de CTAB e de butanol. As extrações foram realizadas em $\mathrm{pH}$ 8,0 mantendo em 5\% $\mathrm{v} / \mathrm{v}$ a concentração de hexanol. O plano experimental e os níveis das variáveis independentes estão mostrados na Tabela I. Utilizou-se como variável resposta a porcentagem de atividade total recuperada de $\beta$-xilosidase $\mathrm{Y}(\%)$. A metodologia se superfície de resposta (MSR) foi utilizada para ajustar os dados a um modelo polinomial de segunda ordem expresso pela Equação 2:

$$
\hat{y}_{i}=b_{0}+b_{1} X_{1}+b_{2} X_{2}+b_{12} X_{1} X_{2}+b_{11} X_{1}^{2}+b_{22} X_{2}^{2}
$$

onde:

$\hat{y}_{i}$ representa a variável de resposta,

$\mathrm{b}_{0}$ - o coeficiente de intercessão,

$b_{1}$ e $b_{2}$ - os coeficientes lineares,

$\mathrm{b}_{11}$ e $\mathrm{b}_{22}$ - os coeficientes quadráticos,

$X_{1}$ e $X_{2}$ representam as variáveis independentes: concentração de CTAB e butanol, respectivamente.

A qualidade do ajuste da equação polinomial do modelo foi expressa pelo coeficiente de determinação $\mathrm{R}^{2}$ e a sua significância estatística foi determinada pelo teste $F$ de Fisher. A superfície de resposta foi traçada utilizando-se o programa STATISTICA for Windows (Statsoft, Inc.) v. 5.0. As concentrações ótimas das variáveis foram obtidas pela análise dos gráficos de curvas de nível das respostas e pelo método numérico do programa "Design-expert".

\section{RESULTADOS E DISCUSSÃO}

O presente trabalho teve como objetivo a otimização do processo de recuperação da enzima $\beta$-xilosidase por micelas reversas. Na Tabela I encontra-se a planilha com os níveis codificados e originais das variáveis independentes: concentração de CTAB e de butanol, segundo o planejamento proposto, bem como os valores de recuperação da enzima $\beta$-xilosidase extraída por micelas reversas do agente tensoativo CTAB em isoctano, hexanol e butanol.

As variáveis foram codificadas de acordo com a equação 3:

$V_{C}=\frac{\left(V_{R}-V_{O}\right)}{\Delta V_{R}}$

(Equação 3)

onde:

$\mathrm{V}_{\mathrm{C}}=$ valor codificado da variável independente

$\mathrm{V}_{\mathrm{R}}=$ valor real da variável independente

$\mathrm{V}_{\mathrm{O}}=$ valor real da variável independente no ponto central $\Delta \mathrm{V}_{\mathrm{R}}=$ valor do passo, isto é $\left(\mathrm{V}_{\mathrm{Rmáx}}-\mathrm{V}_{\mathrm{Rmin}}\right) / 2$.

O delineamento experimental para os vários tratamentos foi baseado em trabalho anterior (Hasmann et al., 2001), o qual revelou que um valor ótimo de recuperação pode ser encontrado na faixa dos parâmetros avaliados. Pelos resultados obtidos (Tabela I), observa-se que valores nulos de recuperação foram obtidos apenas nos ensaios 03 $(0,3 \mathrm{M}$ CTAB e $10 \%$ butanol) e 05 ( $0,2 \mathrm{M}$ CTAB e $5,86 \%$ de butanol). Resultados semelhantes foram também encontrados por Hasmann et al. (2001) em ensaios de recuperação de $\beta$-xilosidase pré-purificada com etanol utilizando 0,2 $\mathrm{M}$ de CTAB e $10 \%$ de butanol. Segundo os autores, este comportamento ocorre devido a excessiva concentração de tensoativo em relação à concentração de butanol presente, ou seja, nesta proporção entre solvente e tensoativo pode ocorrer o deslocamento do equilíbrio para uma região do diagrama de fases onde a formação dos agregados seja diferente da organização em micelas reversas.

Os resultados referentes à análise de variância (ANOVA) dos fatores estudados estão mostrados na Tabela II. Observa-se que apenas os efeitos principais dos fatores CTAB $\left(X_{1}\right)$ e butanol $\left(X_{2}\right)$ não se apresentaram significativos $(p>0,10)$. Neste caso, os coeficientes lineares atribuídos a estes fatores podem ser desprezados ou mesmo eliminados do modelo.

Observa-se, ainda, que a interação entre concentração do tensoativo (CTAB) e do co-solvente (butanol) é al- 
TABELA I - Matriz do planejamento $2^{2}$ completo para a otimização dos resultados de recuperação de $\beta$-xilosidase por micelas reversas de $\mathrm{CTAB}$

\begin{tabular}{cccccc}
\hline \multirow{2}{*}{ Ensaio } & \multicolumn{2}{c}{ Níveis codificados } & \multicolumn{2}{c}{ Níveis originais } & \multirow{2}{*}{ Y (\%) } \\
\cline { 2 - 5 } & CTAB $(\mathrm{M})$ & Butanol $(\%)$ & CTAB $(\mathrm{M})$ & Butanol $(\%)$ & \\
\hline 1 & -1 & -1 & 0,10 & 10 & 33,9 \\
2 & -1 & +1 & 0,10 & 30 & 12,9 \\
3 & +1 & -1 & 0,30 & 10 & 0 \\
4 & +1 & +1 & 0,30 & 30 & 30,6 \\
5 & 0 & $-2^{1 / 2}$ & 0,20 & 5,86 & 0 \\
6 & 0 & $+2^{1 / 2}$ & 0,20 & 34,14 & 10,0 \\
7 & $-2^{1 / 2}$ & 0 & 0,06 & 20 & 18,2 \\
8 & $+2^{1 / 2}$ & 0 & 0,34 & 20 & 23,0 \\
9 & 0 & 0 & 0,20 & 20 & 30,8 \\
10 & 0 & 0 & 0,20 & 20 & 39,7 \\
11 & 0 & 0 & 0,20 & 20 & 34,9 \\
12 & 0 & 0 & 0,20 & 20 & 34,8 \\
\hline
\end{tabular}

TABELA II - Análise de variância dos fatores estudados no processo de extração de $\beta$-xilosidase por micelas reversas de CTAB

\begin{tabular}{lrcrrl}
\hline Fator & \multicolumn{1}{c}{ SQ } & GL & \multicolumn{1}{c}{ MQ } & \multicolumn{1}{c}{ F } & \multicolumn{1}{c}{$p$} \\
\hline$X_{1}$ & 11,01 & 1 & 11,01 & 0,34 & 0,5809 \\
$\boldsymbol{X}_{1}{ }^{2}$ & 199,67 & 1 & 199,67 & 6,17 & $0,0475 * *$ \\
$\boldsymbol{X}_{2}$ & 70,71 & 1 & 70,71 & 2,18 & 0,1897 \\
$\boldsymbol{X}_{2}{ }^{2}$ & 1146,29 & 1 & 1146,29 & 35,43 & $0,0010^{* * *}$ \\
$\boldsymbol{X}_{1} \boldsymbol{X}_{2}$ & 665,64 & 1 & 665,64 & 20,57 & $0,0039^{* * *}$ \\
Erro & 194,09 & 6 & 32,35 & & \\
\hline Total & 2144,94 & 11 & & &
\end{tabular}

$\mathrm{SQ}=$ soma quadrática, $\mathrm{GL}=$ graus de liberdade, $\mathrm{MQ}=$ média quadrática, $\mathrm{R}^{2}=0,91, * *$ Significativo com nível de significância de $95 \%(\mathrm{p}<0,05), * * *$ Significativo com nível de significância de $99 \%(\mathrm{p}<0,01)$

tamente significativa $(\mathrm{p}<0,01)$, o que confirma a existência de uma combinação ótima entre estes dois fatores na extração da enzima. De fato, utilizam-se co-solventes como auxiliares na formação do núcleo interno de micelas reversas de tensoativos cationicos, como o CTAB, pois estes agem como soluções salinas provocando uma repulsão entre as partes hidrofóbicas do tensoativo e aumentando o raio das micelas, o que contribui para o englobamento da proteína.

Através da análise de variância da regressão obtida (Tabela III), pode ser constatado que o modelo é altamente significativo $(p<0,001)$ e apresenta um bom coeficiente de
TABELA III - Análise para regressão do modelo quadrático do processo de extração de $\beta$-xilosidase por micelas reversas de $\mathrm{CTAB}$

\begin{tabular}{lrrrrc}
\hline $\begin{array}{l}\text { Fonte de } \\
\text { variação }\end{array}$ & SQ & GL & MQ & $F$ & $p$ \\
\hline $\begin{array}{l}\text { Modelo } \\
\text { Resíduo }\end{array}$ & 1869,14 & 3 & 623,05 & 18,08 & $0,0006^{* * *}$ \\
$\begin{array}{l}\text { Falta de } \\
\text { ajuste }\end{array}$ & 235,97 & 5 & 47,19 & 3,56 & 0,1625 \\
Erro puro & 39,77 & 3 & 13,26 & & \\
\hline Total & 2144,88 & 11 & & & \\
\hline SQ = soma quadrática, GL = graus de liberdade, MQ $=$ \\
média quadrática $\mathrm{R}^{2}=0,87, * * *$ Significativo com nível de \\
significância de $99 \%(\mathrm{p}<0,01)$
\end{tabular}

determinação $\left(\mathrm{R}^{2}=0,87\right)$, o que indica uma boa representação matemática do processo em estudo, ou seja, $87 \%$ da variação total em torno da média pode ser explicada pelo modelo e os restantes $13 \%$ representam os resíduos. O modelo obtido para descrever a recuperação da enzima $\beta$ xilosidase, na região em estudo, pode ser expresso pela Equação 4.

$\hat{y}=35,05+12,90 X_{1} X_{2}-5,59 X_{1}^{2}-13,39 X_{2}^{2} \quad$ (Equação 4)

onde:

$\hat{y}=$ recuperação da enzima $(\%)$ 
$X_{1}=$ concentração de CTAB $(\mathrm{M})$

$X_{2}=$ concentração de butanol $(\% \mathrm{v} / \mathrm{v})$.

De acordo com a equação do modelo, podem ser obtidos valores máximos de recuperação de 35,05 \pm $6,40 \%$ nas seguintes condições: $\mathrm{pH} 8,0, \mathrm{CTAB} 0,2 \mathrm{M}$, hexanol a $5 \%$ e butanol a $20 \%$. A Figura 1 mostra a superfície de resposta que representa a recuperação da enzima em função das variáveis CTAB e butanol, para o modelo quadrático obtido. Nas condições otimizadas foram realizados novos experimentos e o valor médio de recuperação obtido foi de $38 \%$, o que mostra adequação do modelo aos dados experimentais.

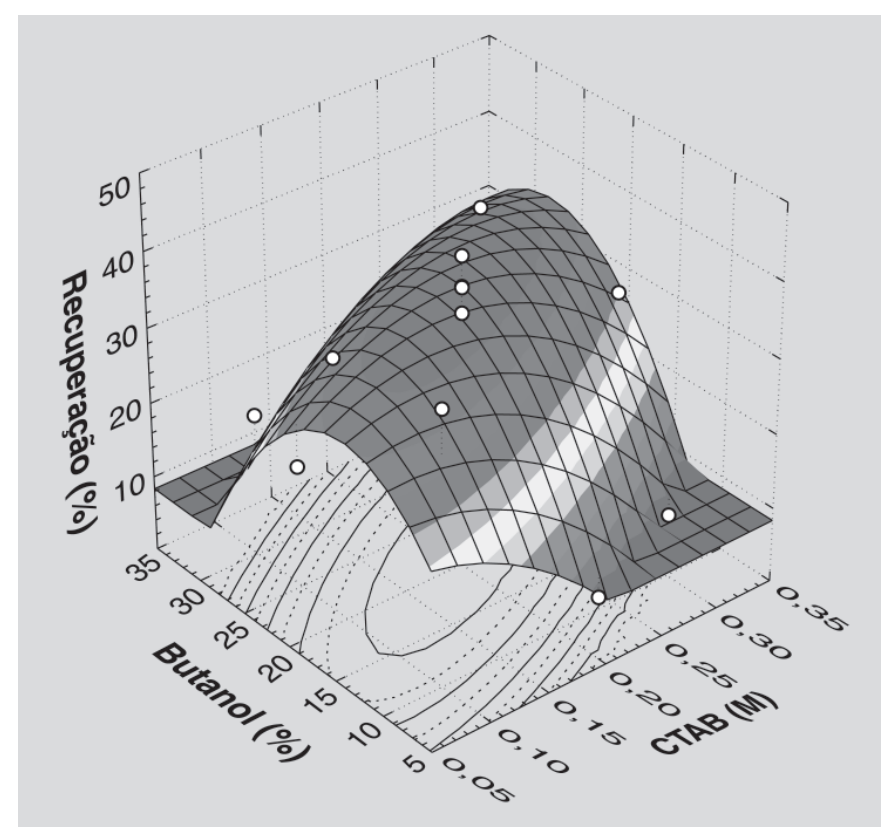

FIGURA 1 - Superfície de resposta que representa a recuperação da enzima $\beta$-xilosidase em função da concentração de CTAB e de butanol.

\section{CONCLUSÕES}

O processo de extração por micelas reversas de CTAB mostrou-se adequado para a recuperação da enzima $\beta$-xilosidase diretamente do meio fermentado. $O$ valor de recuperação obtido experimentalmente nas condições otimizadas (38\%) foi similar ao previsto pelo modelo (35\%), o que demonstra sua adequação aos dados experimentais.

\section{ABSTRACT \\ Optimization of $\beta$-xylosidase extraction process using reversed micellar systems}

$\beta$-xylosidase, produced by Penicillium janthinellum, was extracted by using the reversed micellar system of the CTAB (cetyl trimethyl ammonium bromide) cationic surfactant containing isooctane, hexanol and butanol. The combined effects of CTAB and butanol concentrations on enzyme extraction were studied by using the surface response methodology. As a function of the results, it was proposed a mathematical model to describe the process of $\beta$-xylosidase extraction. This model predicted a maximal enzyme extraction yield of $35.05 \pm 6.4 \%$ under the following conditions: $\mathrm{pH}=8.0, C T A B=0.20 \mathrm{M}$, hexanol $=5 \%(v / v)$, and butanol $=20 \%(v / v)$. Experimentally, $a$ recovery value of about $38 \%$ was attained, and showed that the model is appropriate.

UNITERMS: $\beta$-xylosidase. Reversed micelles. Liquidliquid extraction. Recovery. Hemicellulosic hydrolyzate.

\section{AGRADECIMENTOS}

À Fundação de Amparo à Pesquisa do Estado de São Paulo - FAPESP, à CAPES e ao CNPq, pelo auxílio financeiro e pelas bolsas concedidas.

\section{REFERÊNCIAS BIBLIOGRÁFICAS}

BIELY, P. Microbial xylanolitic systems. Trends Biotechnol., Amsterdam, v.3, p .286-290, 1985.

CORTEZ, E. V., PESSOA-Jr. A. Xylanase and $\beta$-xilosidase separation by fractional precipitation. Process Biochem., London, v. 35, p. 277-283, 1999.

HASMANN, F. A., PESSOA-Jr., A., ROBERTO, I. C. Optimization of $\mathrm{pH}$ and temperature for $\beta$-xilosidase recovery by reversed micelles. Biotechnol. Tech., London, v. 13, p. 239-242, 1999.

HASMANN, F. A., PESSOA-Jr., A., ROBERTO, I. C. Screening of variables in $\beta$-Xilosidase recovery using cetyl trimethyl ammonium bromide reversed micelles. Appl. Biochem. Biotechnol., Clifton, v. 91-93, p. 719-728, 2001. 
KILIKIAN, B. V., BASTAZIN, M. R., MINAMI, N. M., GONÇALVES, E. M. R., PESSOA-Jr, A. Liquid-liquid extraction by reversed micelles in biotechnological processes. Braz. J. Chem. Eng., Campinas, v. 17, p. 2938,2000 .

KREI, G., HUSTEDT, H. Extraction of enzymes by reverse micelles. Chem. Eng. Sci., New York, v.47, p.99-111, 1992.

KUMAR, S., RAMÓN, D. Purification and regulation of the synthesis of a b-xylosidase from Aspergillus nidulans. FEMS Microb.Lett., Amsterdam, v.135, p.287-293, 1996.

LESER, M. E., LUISI, P. L. Application of reverse micelles for the extraction of amino-acids and proteins. Chimia, Zurick, v.44, p.270-282, 1990.

LUISI, P. L., GIOMINI, M., PILEN, M. P., ROBINSON, B. $\mathrm{H}$. Reversed micelles as hosts for proteins and small molecules. Bioch. Biophys. Acta, Amsterdam, v.947, p.209-246, 1988.
MILAGRES, A. M. F., LACIS, L. S. Efficient screening of process variables in Penicillium janthinellum fermentation. Biotechnol. Lett., Middlesex, v.13, p.113$118,1991$.

MILAGRES, A. M. F. Alguns aspectos da regulação de $\beta$ xilanases extracelulares de Penicillium janthinellum. Viçosa, 1988, 79p. [Dissertação de Mestrado. Universidade Federal de Viçosa].

PAN, I-H, YAO, H. J., LI, Y. K. Effective extraction and purification of $\beta$-xylosidase from Trichoderma koningil fermentation culture by aqueous two-phase portioning. Enz. Microb. Technol., Surrey, v.28, p.196-201, 2001.

PESSOA-Jr. A., VITOLO, M. Recovery of inulinase using BDBAC reversed micelles. Process. Biochem., New York, v.33, p.291-297, 1998.

SUNNA, A., ANTRANIKIAN, G. Xylanolitic enzymes from fungi and bacteria. Crit. Rev. Biotechnol., Cleveland, v. 17, p.39-67, 1997.

Recebido para publicação em 18 de junho de 2002. 